\author{
Ophthalmic Res 2010;44:140 \\ DOI: $\underline{10.1159 / 000315532}$
}

\section{Impact of Once Daily versus Twice Daily Application of Adjunctive Timolol on the Intraocular Pressure- Lowering Effect of Latanoprost}

\section{Mohammad H. Nowroozzadeh}

Department of Ophthalmology, Khalili Hospital, Shiraz University of Medical Sciences, Shiraz, Iran

\section{Dear Editor,}

I write concerning the article by Cheng et al. [1], which was published in the June 2009 issue. In that article, it was concluded that timolol $0.5 \%$ once daily was a more potent adjunct to latanoprost than timolol $0.5 \%$ twice daily. Intuitively, we expect that adjunctive timolol has a more beneficial effect on lowering intraocular pressure (IOP) when instilled more frequently. Herein, I offer a plausible explanation for the observed contradiction.

The most consistent finding in the mechanism of latanoprost is a substantial increase in uveoscleral outflow [2]. One well-studied mechanism for the enhancement of outflow by prostaglandins is the regulation of matrix metalloproteinases (MMPs) and remodeling of the extracellular matrix. Other proposed mechanisms include widening of the connective tissue-filled spaces and changes in the shape of cells. All of these mechanisms alter the permeability of tissues of the outflow pathways leading to changes in outflow resistance and/or outflow rates [2].

Recent studies have shown a significant increase in subepithelial collagen density and area in timolol-treated conjunctiva, whereas this finding was not apparent in latanoprost-treated eyes $[3,4]$. Moreover, timolol-treated eyes showed a significant increase in amorphous material as well as a smaller area of empty spaces compared with latanoprost-treated eyes. On the other hand, latanoprost-treated eyes showed an upregulation of MMP-3, which may be the reason for reduced extracellular matrix accumulation in such eyes $[3,4]$. Given that the basics of biochemical reactions are relatively the same in most tissues, these morphological changes may also involve the outflow structures of glaucomatous eyes treated with timolol and/or latanoprost. Thus, increasing the collagen density and amorphous material in timolol-treated eyes may lead to reduction in the permeability of the outflow structures.

Besides the above-mentioned mechanism, it has been shown that timolol affects the choroidal microvasculature. Accordingly, an experimental study revealed that timolol can totally abolish the sympathetic nerve-evoked ocular vasodilation in the rat anterior choroid [5]. This effect is in contrast with the action of prostaglandins that are well-known vasodilators. Vasoconstriction in capillaries of the ciliary body and anterior choroid can increase the hydrostatic pressure within choriocapillaris that subsequently decrease the hydrostatic gradient between IOP and intracapillary pressure leading to a decrease in the uveoscleral outflow.
Overall, regarding the mechanisms discussed above, timolol may partially neutralize the action of latanoprost on increasing uveoscleral outflow. This effect is probably dose dependent and may significantly increase when using twice daily timolol compared with once daily. In the context of latanoprost consumption, this neutralization may overcome the little additional effect of twice daily timolol in decreasing aqueous production. This effect may also present when using timolol alone, but in that situation the role of uveoscleral outflow in the total outflow is proportionally low, and hence, once or twice daily timolol show comparable effects. However, in eyes treated with latanoprost, uveoscleral outflow has a substantially more significant role in controlling IOP, therefore neutralizing its effect could reach clinical significance and lead to the observed contradiction.

There are several other possibilities which can explain the above-mentioned contradiction. Firstly, compared with the once daily application, twice daily timolol may decrease the patients' compliance with consuming both medications. Moreover, when a patient uses timolol twice daily, he or she might have instilled the evening dose close to the latanoprost application leading to its washout.

In conclusion, when compared with the once daily application, twice daily timolol in conjunction with latanoprost may neutralize the effect of latanoprost in such a way that it overcomes its effect on additional decrease in aqueous production. Moreover, the studied cases in the above-mentioned paper were mostly investigated in relatively short durations. Since the assumed morphological change in timolol-treated eyes may significantly increase with time, the long-term adjunctive effect of timolol on latanoprost may not be as significant as its effect in short term. Future studies on long-term adjunctive therapy may show different results.

\section{References}

1 Cheng JW, Li Y, Wei RL: Systematic review of intraocular pressure-lowering effects of adjunctive medications added to latanoprost. Ophthalmic Res 2009;42:99-105.

2 Toris CB, Gabelt BT, Kaufman PL: Update on the mechanism of action of topical prostaglandins for intraocular pressure reduction. Surv Ophthalmol 2008;53(suppl 1):107-120.

-3 Terai N, Schlötzer-Schrehardt U, et al: Effect of latanoprost and timolol on the histopathology of the human conjunctiva. Br J Ophthalmol 2009;93:219-224.

4 Mietz H, Schlötzer-Schrehardt U, Strassfeld C, Krieglstein GK: Effect of latanoprost and timolol on the histopathology of the rabbit conjunctiva. Invest Ophthalmol Vis Sci 2001;42:679-687.

5 Kawarai M, Koss MC: Sympathetic vasodilation in the rat anterior choroid mediated by beta(1)-adrenoceptors. Eur J Pharmacol 1999;386: 227-233.

Mohammad H. Nowroozzadeh

Department of Ophthalmology, Khalili Hospital

Shiraz University of Medical Sciences

Shiraz (Iran)

Tel./Fax +98 711627 9373, E-Mail norozzadeh@gmail.com

\section{KARGER}

Fax +41613061234 E-Mail karger@karger.ch www.karger.com
() 2010 S. Karger AG, Basel

$0030-3747 / 10 / 0442-0140 \$ 26.00 / 0$ 